\title{
3. The metaphysics of the Time-Machine
}

\author{
Alexandros Schismenos \\ The University of Ioannina, Ioannina, Greece \\ ORCID iD: http://orcid.org/0000-0001-8490-4223
}

\section{Abstract:}

The concept of time-travel is a modern idea which combines the imaginary signification of rational domination, the imaginary signification of technological omnipotence, the imaginary concept of eternity and the imaginary desire for immortality.

It is a synthesis of central conceptual schemata of techno-science, such as the linearity and homogeneity of time, the radical separation of subjectivity from the world, the radical separation of the individual from his/her social-historical environment. The emergence of this idea, its spread during the $20^{\text {th }}$ centuryas a major theme of science fiction literature alongside its dissemination as a scientific hypothesis, its popularity with both the public and the scientific community, are indications of the religious role of techno-science.

It is my opinion, finally, that, as a chimera, time-travel is non-feasible and impossible.

In order to support my claims, I will briefly outline the origins of the time-travel concept and its epistemological and metaphysical/ontological conditions. If these conditions prove to be absurd, the logical impossibility of time-travel will have been demonstrated.

\section{Keywords:}

Time travel, Time-Machine, Temporality, Ontology

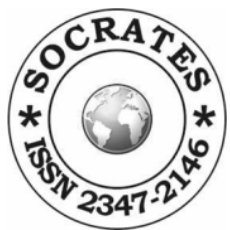




\section{The metaphysics of the Time-Machine}

"Had Pyrrhus not fallen by a beldam's hand in Argos or Julius Caesar not been knifed to death. They are not to be thought away. Time has branded them and fettered they are lodged in the room of the infinite possibilities they have ousted. But can those have been possible seeing that they never were? Or was that only possible which came to pass? Weave, weaver of the wind." (James Joyce, Ulysses)

\section{1) A traveler from the future}

In 2004, after an indecisive presidential election, a series of riots broke out in the United States (John Titor, 2001). Despite the efforts of the newly-elected government, the situation quickly escalated. The disbandment of the Congress in 2008 signified the beginning of the Second American Civil War (John Titor, 2001). International order collapsed, and in early 2015 the brief but catastrophic Third World War began, which ended in the summer of that same year after the nuclear bombing of Washington and Jacksonville (John Titor, 2001). An official truce was signed at the new US capital, Omaha, Nebraska.

These fictitious events do not come from a science fiction story. They are rather part of a "prophecy", one of the first to appear in the 21st century, by a mysterious self-alleged time-traveler from the future named John Titor, who appeared for a short period of time, from November 2000 to March 2001, in various Internet forums (bulletin boards). In his posts he described himself as a soldier from the year 2036 and he offered explanations of his time-traveling based on the quantum physics' "many worlds" interpretation proposed by Everett and elaborated by DeWitt et al., according to which all possible quantum states are actual, so that all possible stories, all possible pasts and possible futures, coexist in an infinite array of parallel, alternative worlds.

Bryce DeWitt wrote: "every quantum transition taking place on every star, in every galaxy, in every remote corner of the universe is splitting our local world on earth into myriads of copies of itself." (DeWitt, 1970, p.40)

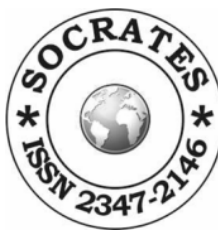


On the basis of this interpretation, John Titor claimed that he came from an alternative future. John Titor's brief rise to fame was based partly on his originality but also on the architecture of the early Internet, which consisted mainly of bulletin boards and semiclosed forums, with few digital celebrities, like a network of whispers - unlike the noise of the open and multiform digital private / public space that social media constitute today.

However, the digital avatar that was 'John Titor' brought together narrative elements and significations that are characteristic of our relationship with modern technology. I use the term 'significations' in the Castoriadean sense, namely, the "pre-eminent element in and which through the social-historical unfolds" (Castoriadis, 1997, p.201), which includes the dominant norms, ideas, representations and attitudes that characterize a specific society.

Ironically, this type of "time traveler" is firmly rooted in his own temporality; He could not have appeared anytime other than before September 11,2001, during the short period propagandized as a fertile "end of history" in the capitalist world (Fukuyama, 1992). He could not have appeared but as a digital avatar within the anonymity of the cyberspace. He could not have become famous (he has inspired a theatrical, a novel, several articles and shows, and a series of imitators) without the diffusion, repeatability and transmissibility of online communication. In a way he was a pioneer of digital science fiction through the direct, semi- private and impersonal Internet communication, where the Narrator is Nobody and the Listener Everybody.

At the dawn of the digital ontological revolution (Schismenos, 2016, p. 57), when technology seemed capable of eliminating Space, both as distance, by making direct communication possible and as a hypostasis, by realizing the immaterial virtual cyberspace, John Titor embodied the other scientific chimera of the technological era: the elimination of Time. What else does the fantasy of time-travel express, if not the subjugation of time, an implicit aspiration to immortality?

The concept of time-travel is a modern idea which combines the imaginary signification of rational domination, the imaginary signification of technological omnipotence, the imaginary concept of eternity and the imaginary desire for immortality.

VOL 6 NO 3 AND 4 (2018) ISSUE- SEPTEMBER AND DECEMBER

ISSN 2347-6869 (E) \& ISSN 2347-2146 (P)

The metaphysics of the Time-Machine By Alexandros Schismenos, Page No. 37-53

DOI: 10.5958/2347-6869.2018.00014.6

DOS: 2018-10-08 DOA: 2018-12-30 DOP: 2019-04-28

Journal Section: Philosophy

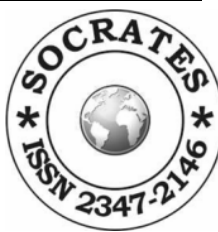


It is a synthesis of techno-science's central conceptual schemata, such as the linearity and homogeneity of time, the radical separation of the subjectivity from the world, the radical separation of the individual from his/her social-historical environment.

The popularity of this idea as a major theme of science fiction literature alongside its dissemination as a scientific hypothesis, are indications of the religious aspirations of techno-science. In my opinion, however, time-travel is a pure chimera, a nonfeasible and impossible idea.

In order to support my statement, I will briefly outline the origins of the concept of the time-machine and its epistemological and metaphysical/ontological presuppositions. If these presuppositions prove to be absurd, the logical impossibility of time-travel will be demonstrated.

\section{2) The origins of a chimera}

In 1895, H. G. Wells published his first novel, titled The Time Machine.

According to James Gleick, this was the first public appearance of the idea of timetravel with the use of a machine (Gleick, 2017, p.7). The novel contains the three elements that constitute the narrative pattern of modern time-travel fiction: The timetraveler, the subject of the adventure, time, the place of the adventure, and the timemachine, the device leading the plot. The time-machine is the central element of the plot, since time is spatialized and neutralized, while the time-traveler's personal history is reduced and condensed to the only important instance, the ride on the time-machine.

Of course, we can find older, even ancient narratives that include some kind of temporal shifting. The Japanese chronicle Nihon Shoki, from 720 A.D., mentions a fisherman by the name Urashima Taro, who visits an undersea palace for three days, only to discover upon his return that three centuries had passed. There are also the story of rabbi Honi ha $\mathrm{M}$ ' agel, from the $1^{\text {st }}$ century A.D., who, according to legend, slept for 70 years and the story of Rip Van Winkle from 1819, who allegedly slept for 20 years (Goldin, 1988). However, these two latter stories are essentially stories of longevity, since both sleepers continue to 
age physically, remaining within the common natural temporality, while the first story is a journey to a mythical heterogeneous temporality, another cosmic dimension (submarine), where the passage of time itself is completely different. None includes the components of the modern myth: the time-machine and time-traveling by technological means.

The concept of the machine is not itself a creation of modernity, but the imaginary significance of mechanical omnipotence is definitely modern. Lewis Mumford, born also in 1895, observed that where capitalism "prospered, it established three main canons for successful economic enterprise: the calculation of quantity, the observation and regimentation of time, ('Time is Money') and the concentration of abstract pecuniary rewards" (Mumford, 1967, p. 279). Following the degradation of religious authority, these three canons "took on the form of moral imperatives, if not neurotic compulsions" (Mumford, 1967, p. 280). The second canon, the regimentation of time, was realized by means of time-measuring machines: mainly by the improvement and prevalence of clocks, with the domination of timetables, and, on the fringe, with the invention of that ultimate chimera, the TimeMachine.

Gleick informs us that, although the phrase "Time Travel" was not established in the English dictionary until 1914 (Oxford English Dictionary), it first appeared on print as early as 1866, in a travel description in Cornhill Magazine, whose author, while traveling by railway, daydreams: "This charm of traveling would become perfect if we could travel in time as well as in space [...] take a fortnight in the 15th century, or still more pleasant, a leap into the 21st" (Gleick, 2017, p. 23). This excerpt indicates the internal relationship of the idea of time-travel with the leveling and homogenizing of time, in a similar fashion to the leveling and homogenizing of space by the railroad. It is indicative of the inner relationship of timetravel to the touristic journey through space.

The precondition of the concept of the time-machine was the invention of the concept of an empty and homogeneous time, a time offered to division and measurement, the exemplar of which is the absolute time $t$ of Newtonian physics. The British tourist on the train consumes space within his personal touristic time and dreams of a similar consumption of time within his personal touristic space by means provided by technology. This fantasy presupposes a different perception of subjectivity as a being separated from the world. It also requires a linear understanding of history, which compresses the multiple,

VOL 6 NO 3 AND 4 (2018) ISSUE- SEPTEMBER AND DECEMBER

ISSN 2347-6869 (E) \& ISSN 2347-2146 (P)

The metaphysics of the Time-Machine By Alexandros Schismenos, Page No. 37-53

DOI: 10.5958/2347-6869.2018.00014.6

DOS: 2018-10-08 DOA: 2018-12-30 DOP: 2019-04-28

Journal Section: Philosophy

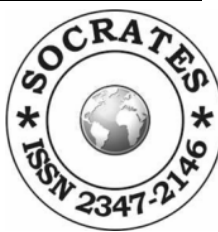


heterogeneous histories in a single progressive historical movement towards the future. However, the idea of traveling through time undermines its very preconditions.

\section{3) The Time-Machine and the concept of progress}

Reinhart Koselleck has argued that the concept of "history pure and simple" or "general history" is an invention dating back to the 18th century in Europe, which corresponds to the imaginary signification of Progress (Koselleck, 2004, p. 103). Even though he finds in the writings of St. Augustine of Hippo the origin of the concepts of an "ordotemporum" (temporal order) and a "historia ipsa" (history itself) these initially stem from God and are meaningful only within the divine plan of salvation. For Augustine, secular history is a mere shadow of Christian Sacred History, which is articulated in six centuries (aetatis), consisting of biblical episodes from the Fall to the Crucifixion. On the contrary, the modern Western conception of progress is secular and bears unique characteristics, namely the "historical determinants of progress and regress, acceleration and delay" (Koselleck, 2004, p. 103), accompanied with the denaturalization of social action by the advance of technology: "It distinguishes modernity from those civilizing processes historically registered in the developed cultures of the Mediterranean, Asia, and pre-Columbian America. The relations of time and space have been transformed, at first quite slowly, but in the nineteenth and twentieth centuries, quite decisively. The possibilities of transport and communication have engendered completely new forms of organization." (Koselleck, 2004, p. 96)

According to the conceptual schema of Progress, heterogeneous local histories are absorbed into a single global progressive History, while the distance between the "Space of Experience", which refers to the past, and the "Horizon of Expectation", which expands towards the future, widens. The German historian argues that, while pre-modern societies sought to ground practical ethics to the accumulated traditional "space of experience" of the past - for example, Machiavelli interprets his contemporary politics by looking back to ancient Roman political history - modernity views the traditional "space of experience" as a source of delay and orients the practical ethics of present action to the horizon of expectation of a utopian future - Marx talks about the future communist society and projects the class struggles of the present to that future.

In this approach the present appears as the place where the experiences of the past and the expectations of the future converge. In the traditional Christian perception,

VOL 6 NO 3 AND 4 (2018) ISSUE- SEPTEMBER AND DECEMBER

ISSN 2347-6869 (E) \& ISSN 2347-2146 (P)

The metaphysics of the Time-Machine By Alexandros Schismenos, Page No. 37-53

DOI: 10.5958/2347-6869.2018.00014.6

DOS: 2018-10-08 DOA: 2018-12-30 DOP: 2019-04-28

Journal Section: Philosophy

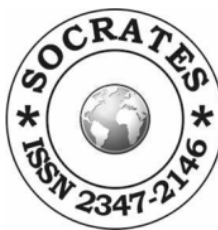


the horizon of expectations was rooted in the space of past experience, while the fulfillment of ultimate salvation was placed outside the historical world. The past is always present in the form of tradition and ritual, while the only hope for a radically different future lies in the transcendence of mortality and the end of history, both of which are acts of God, beyond human power. Conversely, in Western modernity, the horizon of future expectations expands infinitely and its relation to the space of past experience is reversed - the expected future diverges from the experienced past. The future is always present in the form of progress and acceleration, while tradition is something outdated. The fulfillment of future progress lies within the sphere of human responsibility and action.

Progress, which requires a unified temporality, is essentially directed, as a dynamic movement of constant change, against the uniformity of its temporal unity, since it is defined by the expectation of a divergent future, radically different from the past. So, progressive history is characterized by the diversity of its 'historical stages'.

The idea of the Time-Machine combines the notion of an absolute time, independent from events, with the notion that past and future events and "contents" exist independently, on another plane of reality, like Thomas More's Island of Utopia in the $16^{\text {th }}$ century was to be found on different latitudes.

More's Utopia, placed in a distant exotic place but not in a different temporality, corresponds to the social imaginary of the era of the expanding and exploitive European expeditions to America and Africa, when the 'horizon of expectations' was geographical.

The Time-Machine expresses the displacement of utopia from a distant place to a distant time, from geography to history. However, this shift was made possible by the modern uprising against religious authority and the re-emergence of the project of autonomy, the awareness that humans create their own history. The fantasy of the TimeMachine seems like a mockery of this idea of human autonomy, since it is an implicit denial of the conditions of human freedom, namely the uncertainty of the future, the irreversibility of the past and the creativity of the present.

The Time-Machine requires a uniform, homogeneous and linear time, a temporal vacuum, within which one could isolate a particular point of the historical process and reverse its flow, reversing a portion of the temporal flow without reversing the totality of the flow, otherwise the idea of travel becomes meaningless. While the temporal motion of the time-machine is inverted and appears to undermine the continuity of global progress, it is also a local and partial motion by the determinants of regression or acceleration.

VOL 6 NO 3 AND 4 (2018) ISSUE- SEPTEMBER AND DECEMBER

ISSN 2347-6869 (E) \& ISSN 2347-2146 (P)

The metaphysics of the Time-Machine By Alexandros Schismenos, Page No. 37-53

DOI: 10.5958/2347-6869.2018.00014.6

DOS: 2018-10-08 DOA: 2018-12-30 DOP: 2019-04-28

Journal Section: Philosophy

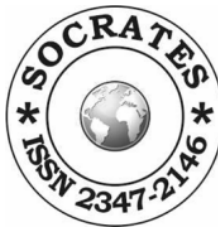


The paradoxes of the Time-Machine originate from the adoption of the linear deterministic paradigm, in order to fulfill a non-deterministic, non-linear movement towards the past or the future by deterministic, technological means. Alfred Jarry, who published his own plans for a Time-Machine, wrote: "It is worth noting that the Machine has two Pasts: the past anterior to our own present, what we might call the real past; and the past created by the Machine when it returns to our Present and which is in fact the reversibility of the Future" (Gleick, 2017, p. 37). And yet, the modern horizon of expectations that inspires the idea of the Time-Machine is based precisely on the non-reversibility of the future.

\section{4) Timelines and charts}

The appearance of a touristic time, a type of social temporality available for personal consumption, in the late 19th century, along with the invention of tourism, made the past "a place to visit", symbolically "present" in archeological sites, museums and galleries. Tourism expanded alongside European colonialism. The findings of archeology, paleontology and geology led to the creation of temporal diagrams; while the layered sediments of geological sections helped the public visualize the fossilized layers of static time.

The modern conception of Time as the $4^{\text {th }}$ dimension of Space is the conceptual basis of the Time-Machine. Ten years after the publication of Wells' The Time-Machine in 1905, Albert Einstein proposed, in his Special Theory of Relativity, a different approach to time, measured in relation to the ultimate and finite speed of light (Einstein, 1905). Every observer with a different frame of reference reaches a different time measurement, thus temporal measurements become relative. Events within the observer's light cone belong to his temporality. Events beyond his light cone cannot have any effect, they do not exist for the observer and neither do they belong to his temporality. The light of the stars reaches us from the past. Likewise, everything we see comes somehow from the past, even in a most recent past, depending on the duration of the journey of the light reflected by the object to our eyes - the visible sight of the object is the past. This theory has an additional consequence, time dilation, which suggests that an observer moving close to the speed of light experiences time passing slower than any observer back on Earth. For a photon which travels exactly at the speed of light time supposedly stands still although this is just a mental experiment, since no massive body can reach the speed of light.

VOL 6 NO 3 AND 4 (2018) ISSUE- SEPTEMBER AND DECEMBER

ISSN 2347-6869 (E) \& ISSN 2347-2146 (P)

The metaphysics of the Time-Machine By Alexandros Schismenos, Page No. 37-53

DOI: 10.5958/2347-6869.2018.00014.6

DOS: 2018-10-08 DOA: 2018-12-30 DOP: 2019-04-28

Journal Section: Philosophy

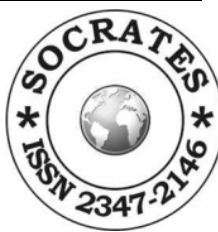


As Hermann Minkowski demonstrated, in relativistic theories time is considered to be the 4 th coordinate, along with the 3 coordinates of space, of any point in the universe. These four coordinates define a "world point". All the world points of an object's path through spacetime form a "world line" and all the "world lines" constitute a "world" or "spacetime continuum". The result produces the static image of a four-dimensional spacetime. Temporal change, the passage of time, ontological novelty and the emergence of alterity are all abolished as illusions, since time becomes geometric.

This description is deterministic and this image of spacetime as a crystallized topography of "world lines" contrasts with other scientific discoveries from the microscopic field of quantum physics, where Heisenberg's principle of uncertainty eliminates any deterministic interpretation. However, if we consider spacetime topographically, the idea of time-travel seems reasonable. On the one hand, it seems reasonable to visit different points of a temporal "landscape" that exists all at once, rather than seeking that which no longer is or does not yet exist. Besides this, the definition of spacetime and the notion of temporal dilation due to velocity essentially equate time-travel to a journey through space, the coverage of a distance. In Minkowski's universe the past and the future are uniform and symmetrical to any given present. On the other hand, if we accept this static image of spacetime, then every world line is already prefixed, every distance has already been covered, every journey in time only happens towards the future in a preordained, "natural" way, and consequently the substantive meaning of the Time-Machine, the artificial abolition of duration, is negated.

The second law of thermodynamics, the increase of entropy, proves the irreversibility of temporal processes (the "Arrow of Time") and the asymmetry of past, present and future. There are irreversible temporal processes intrinsic to the dynamic physical laws, like the CPT symmetry violation in weak force interactions. However, the equations of General Relativity predict entities called "wormholes", like tunnels, joining two distant points of spacetime. Kurt Gödel first demonstrated the possibility of Closed Timelike Curves (CTC) where time flows backwards, which could appear in rotating universes. However, the conditions necessary for the creation of CTC's are incompatible with the scientific observations of our universe. In 1988, physicists Sung-Won Kim and Kip Thorne entertained the possibility of a CTC Time-Machine operating by rotating wormholes (Kim \& Thorne, 1991) to receive Stephen Hawking's response who argued that such a device would

VOL 6 NO 3 AND 4 (2018) ISSUE- SEPTEMBER AND DECEMBER

ISSN 2347-6869 (E) \& ISSN 2347-2146 (P)

The metaphysics of the Time-Machine By Alexandros Schismenos, Page No. 37-53

DOI: 10.5958/2347-6869.2018.00014.6

DOS: 2018-10-08 DOA: 2018-12-30 DOP: 2019-04-28

Journal Section: Philosophy

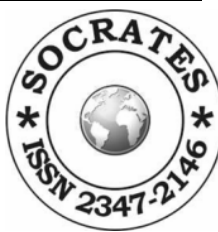


instantly collapse on itself. Hawking's "Chronology Protection Conjecture" was published in 1992 and made the universe, once again, "safe for historians" (Hawking, 1992, p.603).

Whether we consider time as absolute, like Newton did, or relative, like Einstein, the resulting descriptions are nothing more than geometric representations. When we walk on a dark road, illuminated by our flashlight, we are certain that the road ahead, which we do not yet see, exists just as much as the ground beneath our feet and that if the road stops, we can go back. We can visit unknown places without worrying about whether they exist without us. Does the same apply to time? Are the future and the past actually present? Well's time-traveler gives a positive answer with certainty, since he has concrete examples of diagrams, timetables, where time is depicted as a line that bisects space: "Scientific people know very well that Time is only a kind of Space. Here is a popular scientific diagram, a weather record. This line I trace with my figure shows the movement of the barometer [...] Surely the mercury did not trace this line in any of the dimensions of Space [...] but certainly it traced such a line, and that line, therefore, we must conclude was along the Time-Dimension." (Wells, 1895)

The weather record, the railway timetable, the historical maps depict time as a dimension of space, but what kind of time do they actually represent? Each diagram represents the measurement of a process of change, linear, local and limited within an already available scale. But what about the time of all processes? And what about the processes that are not measurable, psychical processes, cultural changes, historical transformations of significations? The idea of the Time-Machine requires that time itself is a diagram, that time itself is finite, measurable and limited. Displayed on the charts are points that indicate limited measurements. But every point differs from the others just by its place in space; it differs in position, not content.

However, time cannot be reduced to a mere difference in position; it also consists of the creation, emergence and destruction of distinct beings and forms. When a composer composes a melody, he/she does not follow a predefined blueprint, he/she creates a form. When we co-operate, we create a collective time. When we meet a lover we create a private, but not personal, inter-subjective time. And every form that appears in time, from the bacterium to our neighbor, to these words, does not just hold a different position, it constitutes another form, of a particular duration, connected in multiple, undetermined ways to time itself. In time, continuity and repetition occur, but the passage of time, the

VOL 6 NO 3 AND 4 (2018) ISSUE- SEPTEMBER AND DECEMBER

ISSN 2347-6869 (E) \& ISSN 2347-2146 (P)

The metaphysics of the Time-Machine By Alexandros Schismenos, Page No. 37-53

DOI: 10.5958/2347-6869.2018.00014.6

DOS: 2018-10-08 DOA: 2018-12-30 DOP: 2019-04-28

Journal Section: Philosophy

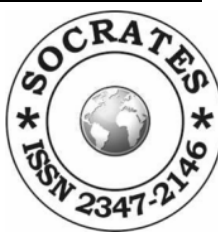


rhythm of creation, growth and decay manifests through alterity, novelty, randomness and freedom.

If the Time-Machine could visit my future, then my future is not under my jurisdiction or my responsibility. The Time-Machine seems to offer atonement from the past, but then the past does not bear importance or real consequence. The concept of the TimeMachine expresses the dominance of technology on history, but only by reducing history to a timetable and thus depriving the autonomous subject of the essence of his/her autonomy: the ability to affect history, to change the present, to become the beginning of a future.

\section{5) Metaphysical assumptions}

In 1976, the American philosopher David Lewis supported the possibility of time-travel. The metaphysical implications of his arguments can help us understand that the fantasy of time-travel is based on two axiomatic assumptions of Western ensemblistic-identitary ontology, which, according to Castoriadis, is the ontology of "being as being determined" (Castoriadis, 1997, p. 211): The separation of the subject from the social-historical world and the spatialization and evacuation of time, the separation of time from events.

Lewis defines time-travel as following: An object time travels if and only if the difference between its departure and arrival times as measured by the surrounding world does not equal the duration of the journey undergone by the object. We can detect the implicit metaphysical/ontological spatialization of time; the perception of time as a kind of displacement, i.e. a change in position. Change is compared to the qualitative variation of a landscape: "Change is qualitative difference between different stages-different temporal parts - of some enduring thing, just as a 'change' in scenery from east to west is a qualitative difference between the eastern and western spatial parts of the landscape" (Lewis, 1976, p. 145). But, one should note that the eastern and western spatial parts of a landscape coexist. The creative and transformative aspects of time, alteration, creation, duration, destruction, and the heterogeneity between temporalities are ignored.

If someone travels from 2018 to 2058 with a Time-Machine and in his/her perspective the journey lasts five minutes, then we must consider two propositions: a) The duration between departure and arrival is five minutes (for him/her) and b) The duration between departure and arrival is 40 years (for the surrounding world). Both propositions

VOL 6 NO 3 AND 4 (2018) ISSUE- SEPTEMBER AND DECEMBER

ISSN 2347-6869 (E) \& ISSN 2347-2146 (P)

The metaphysics of the Time-Machine By Alexandros Schismenos, Page No. 37-53

DOI: 10.5958/2347-6869.2018.00014.6

DOS: 2018-10-08 DOA: 2018-12-30 DOP: 2019-04-28

Journal Section: Philosophy

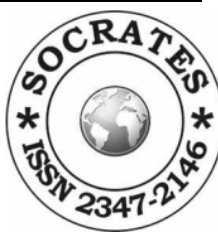


seem equally true and mutually contradictory. Lewis argues that we can avoid this paradox if we separate personal time (the traveler's temporality) from the external time (world temporality): "How can it be that the same two events, his departure and his arrival, are separated by two unequal amounts of time? [...] r reply by distinguishing time itself, external time as I shall also call it, from the personal time of a particular time traveler: roughly, that which is measured by his wristwatch." (Lewis, 1976, p. 146)

Personal time is neither individual psychical time nor the subjective time of consciousness, but the assignment of coordinates of the independent system constituted by the traveler and his wristwatch: "The assignment of coordinates that yields this match is the time traveler's personal time." (Lewis, 1976, p. 146)

So, this does not imply a separation of the subjective consciousness from the objective world, but the separation of a personal reference system from the surrounding world. The metaphysical conditions for this separation are: the symmetry of time, the independence of time periods from their content, and the isolation of the individual; the traveler is uprooted from his social-historical environment.

We can imagine how the psychical temporality of the traveler, his/her unconscious, could be partially isolated from his/her environment. This would happen if the traveler fell into a coma for 40 years. What's the difference? Is his/her subjective certainty that he made the journey in time enough proof? What would be the objective proof that would make his/her subjective claim true? If that existed, whatever it was, it would not belong to his subjective time, but to the surrounding world.

But for the surrounding world, in objective time, 40 years have passed. How can we separate our personal time from external time without presuming a gap between events and time? Does personal time have any more objectivity than merely subjective time or does external time have a somewhat less objectivity than merely objective time?

Is time something outside of us, something separate from our existence, something merely imposed to us? Clearly, we can distinguish between different layers of time, like psychical time, subjective time, social-historical time, natural time. The temporality of my dreams is other than the temporality of my conscious existence, memory, expectation, intersubjective communication, which is other than the temporality that society creates for itself, holidays, anniversaries, institutional processes, historical narratives, which is other than the temporality of the cosmos that we measure. They cannot be reduced to one another, but are correlated and refer to each other. Many differences exist between

VOL 6 NO 3 AND 4 (2018) ISSUE- SEPTEMBER AND DECEMBER ISSN 2347-6869 (E) \& ISSN 2347-2146 (P)

The metaphysics of the Time-Machine By Alexandros Schismenos, Page No. 37-53

DOI: 10.5958/2347-6869.2018.00014.6

DOS: 2018-10-08 DOA: 2018-12-30 DOP: 2019-04-28

Journal Section: Philosophy

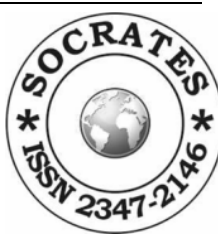


subjective and objective time, but is there any kind of void between them, any empty scission through which one could travel? And if there was this scission between times, by definition timeless, when does the journey start and how long does it take; what time does the traveler's clock count?

"I am not myself a succession of 'psychic' acts, nor for that matter a nuclear I who brings them together into a synthetic unity, but one single experience inseparable from itself, one single 'living cohesion', one single temporality which is engaged, from birth, in making itself progressively explicit, and in confirming that cohesion in each successive present", Merleau - Ponty wrote (Merleau-Ponty, 2002, p. 474).

Experience is conscious life, and it is impossible to divide a subject from the temporal episodes of his/her life. The episodes of a life are united as a whole that concerns the life of a particular subject precisely because of their relations to the world. But individual life gets its meaning by reference to broader, historical temporalities that precede the individual's birth and continue after his/her death. Since the life of consciousness is characterized by the experience of possibilities, the episodes of the life of a subject are unified into a unique temporal consciousness that unifies memory and perception with the experience of future possibilities, which refer to the social-historical.

Lewis recognizes this in part: "what unites the stages (or segments) of a time traveler is the same sort of mental, or mostly mental, continuity and connectedness that unites anyone else. The only difference is that whereas a common person is connected and continuous with respect to external time, the time traveler is connected and continuous only with respect to his own personal time." (Lewis, 1976, p. 147)

How can the traveler be radically isolated from the external world, but still maintain his/her coherence in relation to just his/her personal time, the coherence of which comes from its relation to external time to begin with? And where are we supposed to make the division between the events that relate to personal time and those that only belong to external time? Do the times of the traveler's parents participate in his personal time? Of his/her friends? Of his/her acquaintances? And what about public events? To what extent can the personal system of reference be unbundled from the overall lattice of the socialhistorical field?

Lewis recognizes this problem, but does not provide an answer. He simply warns us: "The more we extend the assignment of personal time outwards from the time traveler's stages to the surrounding events, the more will such events acquire multiple

VOL 6 NO 3 AND 4 (2018) ISSUE- SEPTEMBER AND DECEMBER

ISSN 2347-6869 (E) \& ISSN 2347-2146 (P)

The metaphysics of the Time-Machine By Alexandros Schismenos, Page No. 37-53

DOI: 10.5958/2347-6869.2018.00014.6

DOS: 2018-10-08 DOA: 2018-12-30 DOP: 2019-04-28

Journal Section: Philosophy

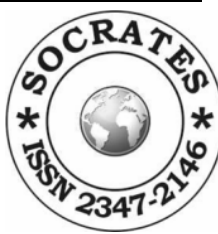


locations. [...] So extension must not be carried too far, lest the location of events in extended personal time lose its utility as a means of keeping track of their roles in the time traveler's history" (Lewis, 1976, p. 147).

If we radically separate personal time from external time, the unity and the coherence of the subject are lost. If we separate objective time from the observing subjectivity, we cannot find a criterion of measurement. Can we strip time from events?

And how can we visit the past and the future, unless they exist now? Time travel presupposes the independent existence of both the past and the future, independent from the creation/destruction of past and future forms, unaltered from time to time. If all times exist simultaneously, then time is actually immobile and the movement of the TimeMachine itself is an illusion.

\section{Conclusions}

"An hour is not merely an hour, it is a vase full of scents and sounds and projects and climates, and what we call reality is a certain connection between these immediate sensations and the memories which envelop us simultaneously with them - a connection that is suppressed in a simple cinematographic vision, which just because it professes to confine itself to the truth in fact departs widely from it - a unique connection which the writer has to rediscover in order to link forever in his phrase the two sets of phenomena which reality joins together." (Proust, 2000, pp. 245-246)

Marcel Proust reminds us of our inner 'time-machine', memory, which weaves together the images of the individual imagination and the social-historical imaginary, of our inner temporality and of the world, in a tapestry of implicit details that constitutes the cohesion and meaning of an individual life within the social-historical time, precisely because life is time. As Castoriadis said: "Being is time - and not in the horizon of time." (Castoriadis, 2008, p. 258)

Time cannot be represented by spatial coordinates; what is depicted by coordinates is a chart. Time is not measured by wristwatches; wristwatches measure the reciprocating movement of the clock hands on the dial or the vibrations of a quartz crystal. Every measurement of time is arbitrary and abstract. But the direction of events, the temporal flow, and the passage of time is not arbitrary. Two dates are never the same, not only

VOL 6 NO 3 AND 4 (2018) ISSUE- SEPTEMBER AND DECEMBER

ISSN 2347-6869 (E) \& ISSN 2347-2146 (P)

The metaphysics of the Time-Machine By Alexandros Schismenos, Page No. 37-53

DOI: 10.5958/2347-6869.2018.00014.6

DOS: 2018-10-08 DOA: 2018-12-30 DOP: 2019-04-28

Journal Section: Philosophy

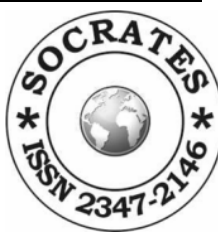


numerically, but in content and in relation to each particular individual in a particular society.

The actual, imaginary and social significance of events, along with the consequences of our actions, creates the asymmetry of past, present and future. Historical events do not just wait for their turn to appear on the world scene, they are consequences of people's actions and have their significance within the social-historical temporality, according to the dominant social imaginary significations. The social imaginary creates the representation of the past and of the future, the space of experience and the horizon of expectations, bestows time with meaning. There are significant dates; scissions in history, but not empty scissions. A tragic example is the drop of the atomic bomb on Hiroshima on August 6, 1945, which brought forward a new, apocalyptic horizon of uncontrollable, destructive expectations. As Günther Anders reminds us: "We really don't know, nor do they who control the Apocalypse: for they too are 'we', they too are fundamentally incompetent. That they too are incompetent, is certainly not their fault; rather the consequence of a fact for which neither they nor we can be held responsible: the effect of the daily growing gap between our two faculties; between our actions and our imagination; of the fact, that we are unable to conceive what we can construct; to mentally reproduce what we can produce; to realize the reality which we can bring into being." (Anders \& Eatherly, 1961, pp. 11-12) It is a scission in history that signifies a "Before" and an "After" but even this event is not isolated in its uniqueness. It is tied with visible and explicit ties to August 9, the nuclear bombing of Nagasaki, in the same constellation of the instant horror with an unlimited duration. It is also connected with the broader world and history asymmetrically as an irreversible event, with a space of experience refracted by myriad individual tragedies and a horizon of expectation unified by the social-historical threat of human extinction.

The human desire for immortality, which is deeply rooted in the Unconscious that ignores the fact of death, is transformed into the social aspiration to eternity that religion, and now also techno-science, promises. Time-travel is the modern, technical form of the desire for immortality. If one can travel freely in time, surely one can avoid death. It is a fantasy that promises atonement without responsibility and promotes the social imaginary signification of technological omnipotence. It is a simplisticidea that reduces time to a temporal geometric abstraction.

But it is also an idea indicative of the unlimited possibilities of human imagination, which is the immanent transcendence that creates the atemporal (mathematics) and the

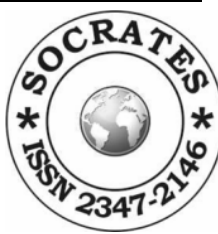


eternal (metaphysics), despite being rooted in the brief temporality of mortality. Imagination allows us to think of time-travel in spite of the fact that it is impossible. Our imagination also allows us to question authority and the predominant social temporality and imagine a different, free and common future, and try to create it democratically by assuming our responsibility for the present, without expecting time travelers to come and save us.

\section{References:}

1. Anders, G., \& Eatherly, C. (1961). Burning Conscience: The case of the Hiroshima pilot, London: Weidenfeld and Nicholson.

2. Castoriadis, C. (1997). The Castoriadis Reader, ed. D.A. Curtis, Oxford: Blackwell.

3. Castoriadis, C. (2008). Fait e à faire. Les Carrefours du labyrinthe, Paris: Points.

4. DeWitt, B. S. (1970). 'Quantum Mechanics and Reality', Physics Today 23 (9): 30-40.

5. Einstein, A. (1905). 'On the electrodynamics of moving bodies', Annalen Phys. 17: 891-921.

6. Fukuyama, F. (1992). The End of History and the Last Man, New York: Free Press.

7. Gleick, J. (2017). Time Travel. London: $4^{\text {th }}$ Estate.

8. Goldin, J. (1988). 'On Honi the Circle Maker: A demanding prayer', Studies in Midrash and Related Literature, Philadelphia: Jewish Publication Society.

9. Hawking, S. W. (1992) 'Chronology Protection Conjecture', Physics Review D. 46 (2): 603-611.

10. Kim, S. W., \& Thorne, K. S. (1991) 'Do vacuum fluctuations prevent the creation of closed timelike curves?', Physical Review, D. 43 (12): 3929-3947.

11. Koselleck, R. (2004). Futures Past. New York: Columbia University Press.

12. Lewis, D. (1976). 'The Paradoxes of Time Travel'. American Philosophical Quarterly 13 (2): 145-152.

13. Merleau-Ponty, M. (2002). Phenomenology of Perception, tr. C. Smith, London: Routledge.

14. Mumford, L. (1967). The myth of the machine I: Technics and Human Development. N. York: Harcourt Brace.

15. Proust, M. (2000) Time Regained, tr. A. Mayor \& T. Kilmartin, London: Vintage Books.

16. Schismenos, A. (2016). "The ontological revolution. On the phenomenology of the Internet. SOCRATES 4 (2): 56-67.

17. Titor, J. (2001), Original posts retrieved from http://www.johntitor.com/ (last visit, December 28, 2018, 21.07)

18. Wells, H. G. (1895) The Time Machine, London: Heinemann.

VOL 6 NO 3 AND 4 (2018) ISSUE- SEPTEMBER AND DECEMBER

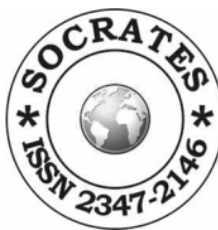




\section{Cite this article:}

The metaphysics of the Time-Machine

\section{Citation Format: APA}

Alexandros, S. (2019). The metaphysics of the Time-Machine. SOCRATES, 6(3 and 4), 37-53.

Retrieved from https://www.socratesjournal.com/index.php/SOCRATES/article/view/359

\section{For more citation formats, visit:}

https://socratesjournal.com/index.php/SOCRATES/article/view/359

\section{Copyright and permissions:}

Copyright (c) 2019 Schismenos Alexandros

\section{(c) (i) \$}

The metaphysics of the Time-Machine by Schismenos Alexandros is licensed under a Creative Commons Attribution-NonCommercial 4.0 International License.

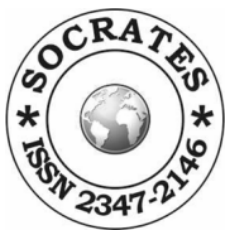




\section{Attribution-NonCommercial 4.0 International (CC BY-NC 4.0)}

This is a human-readable summary of (and not a substitute for) the license. Disclaimer.

\section{You are free to:}

Share - copy and redistribute the material in any medium or format

Adapt - remix, transform, and build upon the material

The licensor cannot revoke these freedoms as long as you follow the license terms.

\section{Under the following terms:}

Attribution - You must give appropriate credit, provide a link to the license, and indicate if changes were made. You may do so in any reasonable manner, but not in any way that suggests the licensor endorses you or your use.

NonCommercial - You may not use the material for commercial purposes.

No additional restrictions - You may not apply legal terms or technological measures that legally restrict others from doing anything the license permits.

\section{Notices:}

You do not have to comply with the license for elements of the material in the public domain or where your use is permitted by an applicable exception or limitation.

No warranties are given. The license may not give you all of the permissions necessary for your intended use. For example, other rights such as publicity, privacy, or moral rights may limit how you use the material. 


\section{Author Self Archiving Policy}

http://www.sherpa.ac.uk/romeo/search.php?issn=2347-2146

\section{Summary:}

Socrates journal does not allow authors to post items submitted to the journal on personal Not for Profit websites or institutional repositories or on any other website prior to publication and after publication. They can only share web links to their published article after publication. The journal, however, permits "author self-archiving" 24 months after the publication of the article.

Published Authors can download and print their article in PD Format but can not share it online on any website.

\section{Preprint (Archiving and sharing online not allowed)}

A preprint is a version of the article before it has been peer-reviewed for publication. The term may refer either to articles at an early stage of preparation or to articles at the last stage before submission for peer review. In the latter case the article is, of course, well-developed and ready for critical review and, if only minor revisions are needed as a result of peer review, a late-stage preprint may be very little different from the final article.

\section{Post print/Final post-print}

\section{(Archiving and sharing online not allowed)}

A post-print is the final version of the article that the author sees before it is published. A post-print has been peer reviewed and the changes and revisions required by the reviewers have been incorporated. However, the author's final post print and the published version are effectively the same.

There would be no responsibility of the Journal Socrates or any member of the Journal on the items submitted/posted by the authors and readers on any personal Not for Profit websites or institutional repositories or website or anywhere on the Internet. In the case of Breach from the side of the author, the Journal will remove the shared article from its published issue.

For more information please feel free to write an e-mail to: editor@socratesjournal.com

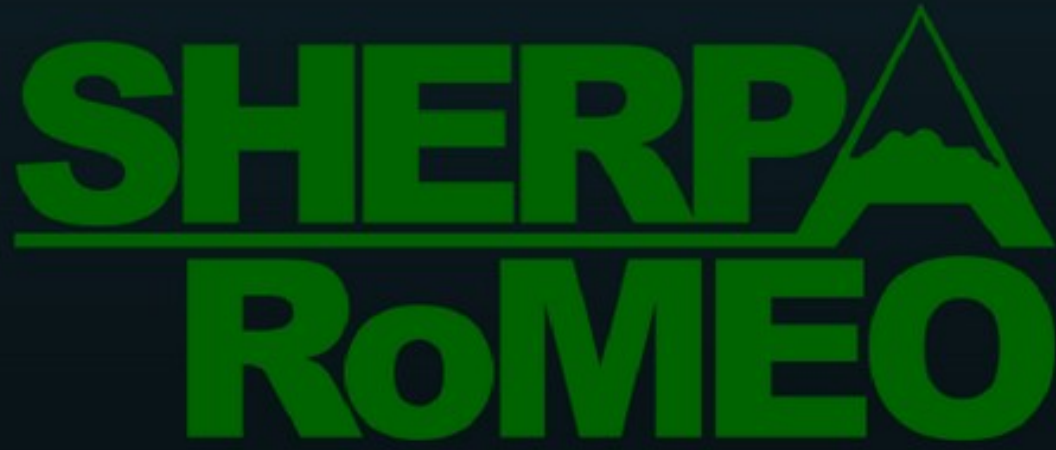

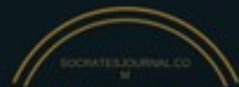

DO NOT SHARE

ONLINE 